\title{
Layer-by-Layer technique employed to construct multitask interfaces in polymer composites
}

\author{
Luísa Sá Vitorino ${ }^{1 *}$ and Rodrigo Lambert Oréfice ${ }^{1}$ \\ ${ }^{1}$ Department of Metallurgical and Materials Engineering, Universidade Federal de Minas Gerais - UFMG, \\ Belo Horizonte, MG, Brazil \\ *luisavitorino@hotmail.com
}

\begin{abstract}
The properties of glass fiber-reinforced polymer composites are closely related to the fiber-matrix interface. Interfacial treatments to improve mechanical properties are usually limited to enhance interfacial adhesion. In this work, Layer-by-Layer (LbL) technique was introduced to build a novel interface in polymer composites. Different numbers of bilayers of poly(diallyldimethylammonium chloride) and poly(sodium 4-styrenesulfonate) with carbon nanotubes were deposited through LbL on the surface of woven glass fibers (GFs). Polypropylene composites containing the modified GFs were prepared by compression molding. Thermogravimetric analysis, scanning electron microscopy and Raman spectroscopy proved that multilayers of polymers with carbon nanotubes could be deposited on GFs surface. Mechanical tests on composites with modified GFs revealed an increase in Flexural Modulus and toughness. The overall results attested that the LbL technique can be used to design interfaces with different compositions to perform diverse tasks, such as to improve the stiffness of composites and to encapsulate active nanocomponents.
\end{abstract}

Keywords: carbon nanotubes, composites, glass fibers, interface, layer-by-layer.

\section{Introduction}

Polymer composites have intrinsic interfaces among their contituents that are responsible for many of the properties of the system. High levels of interfacial interactions between fibers and polymer matrices are considered critical for an efficient stress transfer and, consequently, high mechanical properties ${ }^{[1,2]}$. Many treatments have been studied and used to improve adhesion between the components of polymer composites, including the use of silane coupling agents, polymer grafts and plasma treatments ${ }^{[2-4]}$. These treatments are often successful in improving the adhesion between fibers and polymer matrices, but seldom provide other functionalities to the interface of polymer composites.

Glass fiber-reinforced polymers have been extensively used as materials for weight reduction with many engineering applications due to their high strength and specific stiffness. Glass fibers (GFs) have developed an important role as reinforcement on components manufactured by diverse industrial sectors. Their high mechanical properties associated with good heat resistance and low cost have attracted glass fibers to attention ${ }^{[5-6]}$. Regarding structural applications (e.g. automotive, aerospace, construction), woven glass fiber fabric composites have been considered due to their deformation characteristics and stability. Moreover, polypropylene-glass fiber composites have been increasingly employed in advanced applications since polypropylene presents low density, low cost and easy processing ${ }^{[7]}$.

When glass fibers are incorporated into a polymeric matrix, the properties of the fiber-matrix interface affect the composite performance significantly. A good interfacial adhesion can create an efficient load transfer from the polymer to the fiber, reducing stress concentrations and improving composite mechanical properties ${ }^{[1]}$. Glass fiber

reinforced polymers began to present great improvements in their properties since the starting of using glass fibers with chemical treatments. Traditional treatments as sizings act by increasing the adhesion on interface but they are limited to increase some of the mechanical properties ${ }^{[5,8]}$.

In this present work, we introduce a new way for modifying glass fibers by using the Layer-by-layer technique. Layer-by-Layer ( $\mathrm{LbL})$ technique is based on the consecutive adsorption of oppositely charged polyelectrolytes. Two oppositely charged layers represent one bilayer which can be deposited until the quantity of interest. Compared to other self-assembly methods, LbL can be used to combine a variety of species in nanoscale, merging properties of each material to introduce specific new functions. The ability of LbL to control the thickness of the coating, the economic use of materials and the use of multiple nanocomponents represent a great advantage over other techniques ${ }^{[9-11]}$.

In this work, the hypothesis that the LbL technique could be used to build designed interfaces in polymer composites was tested. The surface of glass fiber fabrics was modified by depositing, via the LbL technique, multilayers of poly(diallyldimethylammonium chloride) (PDDA) and poly(sodium 4-styrenesulfonate) (PSS). The modified GFs were then incorporated into a polypropylene matrix. It was also tested the hypothesis that the LbL technique would allow the incorporation of nanocomponents (such as carbon nanotubes) within the LbL layers. These nanocomponents are useful for introducing new functionalities on composites, such as to increase the stiffness, thermal and electrical properties $^{[5,12,13]}$. Mechanical properties will be assessed in this work aiming structural applications. 


\section{Materials and Methods}

\subsection{Materials}

Poly(diallyldimethylammonium chloride) (PDDA) solution $20 \mathrm{wt} \%$ in water was purchased from Sigma Aldrich ${ }^{\circledR}$. Average molecular weight of PDDA was 200,000-350,000 $\mathrm{g} \mathrm{mol}^{-1}$. The solution was diluted to $2 \mathrm{wt} \%$ using deionized (DI) water (18M $\Omega . \mathrm{cm})$. Poly(sodium 4-styrenesulfonate) (PSS) in powder was purchased from Sigma Aldrich ${ }^{\circledR}$. Average molecular weight of PSS was $70,000 \mathrm{~g} \mathrm{~mol}^{-1}$. DI water $(18 \mathrm{M} \Omega . \mathrm{cm})$ was used for preparing a solution of PSS $2 \mathrm{wt} \%$. Multiwall carbon nanotubes carboxylic acid functionalized (MWCNT-COOH) were purchased from Sigma Aldrich ${ }^{\circledR}$ and produced by Nanocyl ${ }^{\circledR}$ (Belgium). The nanotubes had an average diameter of $9.5 \mathrm{~nm}$, average length of $1.5 \mu \mathrm{m}$ and carbon basis $>80 \%$. Functionalization was superior to $8 \mathrm{wt} \%$. Bidirectional $\left(0^{\circ} / 90^{\circ}\right)$ glass fiber fabric was purchased from Casa da Resina ${ }^{\circledR}$, located in Belo Horizonte, Brazil. It was a woven glass fabric (E-type glass fibers having density of $2.60 \mathrm{~g} / \mathrm{cm}^{3}$ ) with a specific mass of $120 \mathrm{~g} / \mathrm{m}^{2}$, produced by Owens Corning ${ }^{\circledR}$. It will be referred in the text as commercial fibers. Polypropylene homopolymer PH $0950^{\circledR}$ was purchased in pellets from Braskem $^{\circledR}$. Density of the polypropylene was $0.90 \mathrm{~g} / \mathrm{cm}^{3}$ according to manufacturer.

\subsection{Preparation of MWCNT-COOH suspension}

A quantity of $300 \mathrm{mg}$ of carbon nanotubes functionalized with carboxylic acid groups was dispersed in $1 \mathrm{~L}$ of aqueous solution of PSS $2 \mathrm{wt}^{\%}{ }^{[14]}$. The suspension was sonicated for $2 \mathrm{~h}$ and then placed for $30 \mathrm{~min}$ on tip sonicator, $20 \mathrm{kHz}$, $40 \%$ amplitude $(180 \mathrm{~W})$ with intermittent cycle 40 s on $/ 20$ s off. Those parameters were previously evaluated and adjusted in order to get the lowest sonication time while maintaining the sample homogeneous. This was tested consecutively every 10 min until achieving a homogeneous dispersion. Ice bath was used to avoid suspension heating. A $10 \mathrm{ml}$ fraction was placed on total rest for qualitative analysis of the suspension stability during 4 weeks.

\subsection{Pre-treatment of glass fibers}

The commercial glass fiber fabrics were cut to the dimensions $180 \mathrm{~mm} \times 240 \mathrm{~mm}$ and heated up to $650^{\circ} \mathrm{C}$ for $1 \mathrm{~h}$. After that, samples were immersed in a nitric acid solution $\left(\mathrm{HNO}_{3}, 20 \% \mathrm{v} / \mathrm{v}\right)$ at $25^{\circ} \mathrm{C}$ for $24 \mathrm{~h}$ and dried at $60^{\circ} \mathrm{C}$ for $24 \mathrm{~h}$ in order to remove the commercial sizing. Subsequently, samples were immersed in $600 \mathrm{ml}$ of hydrogen peroxide solution $(30 \% \mathrm{v} / \mathrm{v})$ at $75^{\circ} \mathrm{C}$ for $45 \mathrm{~min}$. $30 \mathrm{ml}$ of ammonium hydroxide solution $(30 \% \mathrm{v} / \mathrm{v})$ was added dropwise. After $5 \mathrm{~min}$, samples were washed with DI water and dried on oven at $60^{\circ} \mathrm{C}$ for $2 \mathrm{~h}$. The purpose of this step was to increase the concentration of hydroxyl groups on the surface of the fibers ${ }^{[15]}$. The glass fibers from this procedure will be referred in the text as untreated glass fibers (GF-untreated). No characterization was performed for the commercial sizing since the main interest at this stage rested on its elimination to start the coating procedure ${ }^{[16]}$.

\subsection{LbL modification of glass fibers}

For the coating process, untreated glass fabric was used as the substrate for the LbL procedure. LbL steps are illustrated in Figure 1. First, glass fiber fabrics were immersed in the PDDA $2 \mathrm{wt} \%$ cationic solution for $5 \mathrm{~min}$. Then, samples were rinsed with DI water for $2 \mathrm{~min}$ and slightly dried under nitrogen stream for $1 \mathrm{~min}$. Reduced washing stages (even less than $2 \mathrm{~min}$ ) are commonly used on LbL procedures ${ }^{[10,17,18]}$. After the deposition of the first layer positively charged, the sample was immersed in the $0.30 \mathrm{mg} \cdot \mathrm{ml}^{-1} \mathrm{MWCNT}-\mathrm{COOH} / \mathrm{PSS}$ anionic suspension for $5 \mathrm{~min}$, followed by a new wash and dry cycle. From the third deposition cycle on, the immersion time in cationic and anionic suspensions was reduced to $2 \mathrm{~min}$. Two distinct procedures were performed, with deposition cycles of 5 bilayers and 20 bilayers. The glass fibers resulting from those procedures will be referred as GF-5BL and GF-20BL.

\subsection{Production of bidirectional composites}

Pure polypropylene (PP) sheets of $0.45 \mathrm{~mm}$ in thickness were fabricated by compression molding at $220^{\circ} \mathrm{C}$ and $30 \mathrm{bar}$ using a CARVER 4386 press. Composites were prepared by compression molding using a steel mold with cavity dimensions of $80 \mathrm{~mm} \times 11 \mathrm{~mm} \times 2 \mathrm{~mm}$. Initially, five PP sheets were interlaid with four layers of glass fiber fabric on the cold mold. The press was preheated to $210^{\circ} \mathrm{C}$. The mold was taken to the hot press and a minimum pressure (close to zero) was applied for $2 \mathrm{~min} 30 \mathrm{~s}$. The pressure was relieved to zero and returned to contact condition for $30 \mathrm{~s}$. After that, the pressure was increased to 5 bar every minute up to $30 \mathrm{bar}$, remaining for $1 \mathrm{~min} 30 \mathrm{~s}$. The mold was then removed from the hot press and cooled during $15 \mathrm{~min}$ under cold press (SAGEC) to $25^{\circ} \mathrm{C}$ and 20 bar.

\subsection{Characterization}

The scanning electron microscopy (SEM) images of GFs were obtained on a Quanta FEG 3D FEI system at an acceleration voltage of $5 \mathrm{kV}$. A $5 \mathrm{~nm}$ platinum coating was sputtered onto the surface of GFs to minimize the charging

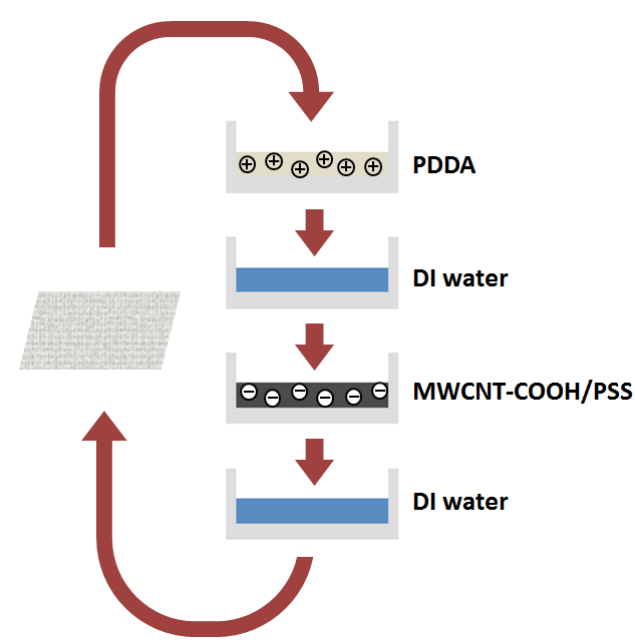

Figure 1. Representation of the Layer-by-Layer procedure. 
effects. The cross sections of modified GFs were obtained by transverse cutting. Individual glass fibers were mounted on cardboard frames and were cut off using a saw blade to get a plane perpendicular to the fiber direction. Moreover the modified GFs were assessed by focused ion beam scanning electron microscopy (FIB-SEM) for evaluation of the coating thickness. The fibers were FIB-milled with a gallium $\left(\mathrm{Ga}^{+}\right)$ ion beam current of $1 \mathrm{nA}$ and with the acceleration voltage of $30 \mathrm{kV}$. The ion beam was used for milling, not for imaging. The cross-sectioned face was polished with the low beam current prior to imaging with SEM since $\mathrm{Ga}^{+}$ions could be deposited in the cross sectioned wall impeding its perfect visualization.

Thermogravimetric analyses (TGA) for the untreated and modified glass fibers were performed on an instrument EXSTAR TG/DTA 7200 with air atmosphere, $30 \mathrm{~mL} / \mathrm{min}$ flow and a heat rate of $10^{\circ} \mathrm{C} / \mathrm{min}$.

Raman spectra for the MWCNT-COOH and the LbL modified glass fibers were obtained on a Jobin Yvon/Horiba LABRAM-HR 800 spectrograph equipped with a He-Ne laser $(632.8 \mathrm{~nm})$. The Raman signal was collected by a microscope Olympus BX-41 provided with objectives (10x, 50x and 100x). The detector used was a $\mathrm{N}_{2}$ liquid cooled CCD of Spectrum One, back illuminated. Depending on the sample background fluorescence, the acquisition time ranged from $10 \mathrm{~s}$ to $120 \mathrm{~s}$ and the laser power from $0.08 \mathrm{~mW}$ to $8 \mathrm{~mW}$. To improve signal/noise ratio, spectra were acquired 10-30 times.

Density measurements of the composites were done accordingly to ASTM D792 - Method A, using water as immersion liquid. The constituents content of the composites were obtained according to ASTM D3171 (procedure G, matrix burnoff in a muffle furnace) at $650^{\circ} \mathrm{C}$ during $1 \mathrm{~h}$.

Calorimetric analysis of the composites using differential scanning calorimetry (DSC) was performed by EXSTAR DSC 7020 equipment at the heating rate of $10^{\circ} \mathrm{C} / \mathrm{min}$. Tests were conducted on $9-10 \mathrm{mg}$ samples from $20^{\circ} \mathrm{C}$ to $220^{\circ} \mathrm{C}$ (first heating) and melting enthalpy and crystallization degree were evaluated. Relative crystallinity $\left(\mathrm{X}_{\mathrm{c}}\right)$ was calculated as the ratio between the value of the melting enthalpy and the theoretical value of the melting enthalpy for the completely crystalline polypropylene $(207 \mathrm{~J} / \mathrm{g})^{[7]}$. Polypropylene directly impregnated on the bidirectional glass fiber fabric containing few fiber segments was extracted from the composite plate in order to get the DSC samples.

Flexural measurements for the bidirectional composites were done according to ASTM D790 - Procedure A, flat wise direction. Data were collected from minimum 5 specimens which were cut and prepared from the composite plates. The specimen dimensions were $12.7 \mathrm{~mm} \times 50.0 \mathrm{~mm} \times 2.0 \mathrm{~mm}$. A universal testing machine INSTRON 5965 equipped with a $5 \mathrm{KN}$ load cell and crosshead speed of $0.90 \mathrm{~mm} / \mathrm{min}$ was used. The samples were cryo-fractured under liquid nitrogen (30min immersion) and the fracture surfaces of the composites were studied using a scanning electron microscope (FEI Model Inspect S50) at an acceleration voltage of $15 \mathrm{kV}$. A $5 \mathrm{~nm}$ platinum coating was sputtered onto the surface to minimize the charging effects.

\section{Results and Discussion}

\subsection{MWCNT-COOH suspension stability}

Before sonication of the carbon nanotubes in PSS, aggregates were initially being deposited into the bottom of the beaker. After $2 \mathrm{~h} 30 \mathrm{~m}$ of sonication, the suspension became totally dark and homogeneous. No aggregates were found on the bottom of the beaker after a closer inspection. The appearance has remained the same after four weeks without visible aggregates or sedimentation. Figure 2 shows the dispersion state of the sample as a function of time.

Carbon nanotubes in suspension represent a kinetically stable system rather than thermodynamically. Thus, sedimentation and aggregation may occur over time ${ }^{[19]}$. Since the dispersion was an intermediate stage in this work and it was used immediately after in the LbL deposition step, the observed stability may be sufficient. The good dispersion of carbon

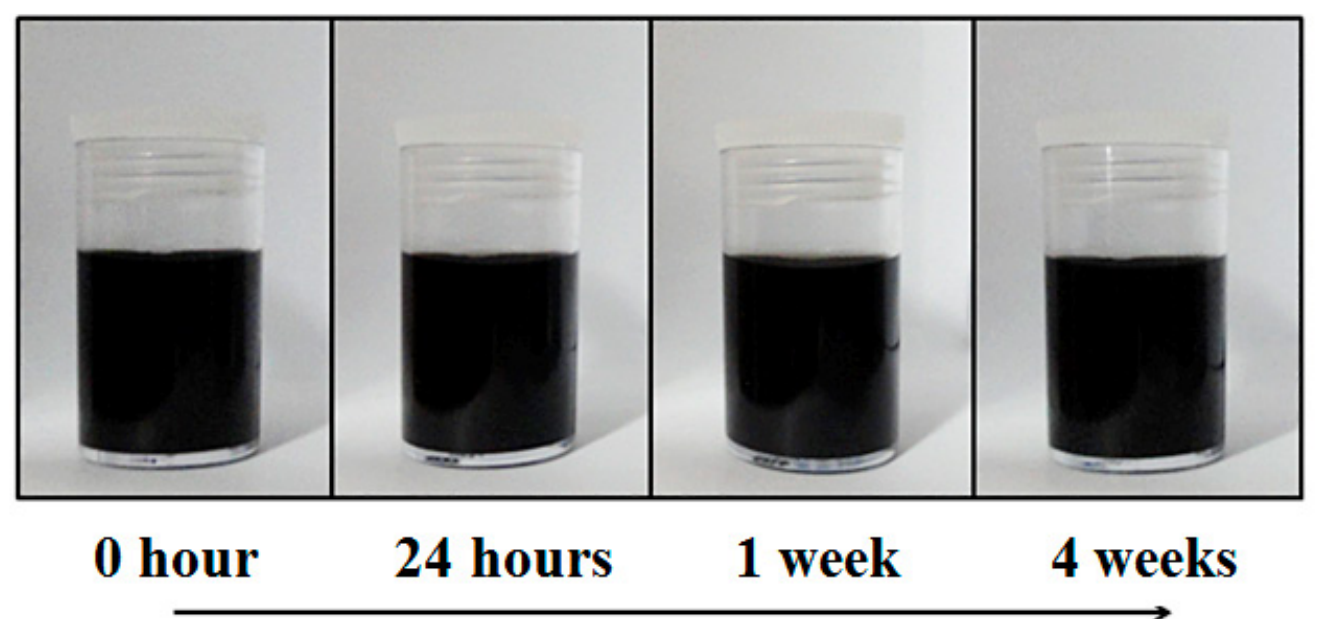

Figure 2. Dispersion state of MWCNT-COOH/PSS suspension as function of time. 
nanotubes in PSS can be explained by the presence of aromatic rings which have a strong affinity for graphitic surfaces via $\pi$-stacking. Typical effective dispersants are polymers consisting of repetitive units of an alkyl chain and aromatic rings, exploiting both the $\pi$-stacking on the surface of CNTs and the Van Der Waals attractions between the hydrophobic part of the surface of nanotubes and the alkyl parts ${ }^{[20]}$.

\subsection{Glass fibers characterization}

The pre-treatment relative to sizing removal was evaluated by SEM by comparing the morphology of commercial glass fiber with the untreated glass fiber. Figure 3 shows the images of commercial (Figure 3a) and untreated (Figure 3b) glass fibers. The average fiber diameter is $15 \mu \mathrm{m}$. The presence of a homogeneous coating is observed over the entire surface on the commercial fiber. After the cleaning treatment, the surface appearance became smooth and clean. The straight lines seen on the borders indicate the absence of a coating.
The LbL procedure (5BL and 20BL) changed the cleaned glass fiber fabric coloration from its original white to dark gray, that could be associated with the deposition of the carbon nanotubes. The 20BL sample became distinctly darker, suggesting a larger amount of deposited carbon nanotubes. Moreover, the water used during the washing step presented a greyish coloration during the first minute of washing, indicating that weakly adsorbed carbon nanotubes were removed and thus preventing cross-species contamination.

After the LbL procedure, 5BL and 20BL modified glass fibers were analyzed by SEM as also illustrated in Figure 3. It is possible to observe the presence of carbon nanotubes on GF-5BL surface. The general appearance is still smooth, preserving the straight lines on the borders similar to the untreated fibers. This could be associated with the very thin coating seen in the sectioned view obtained by FIB milling (Figure 4a) with thickness 100-200nm. Meanwhile, the surface morphology has dramatically changed for 20 bilayers deposition. A high increase on surface roughness is
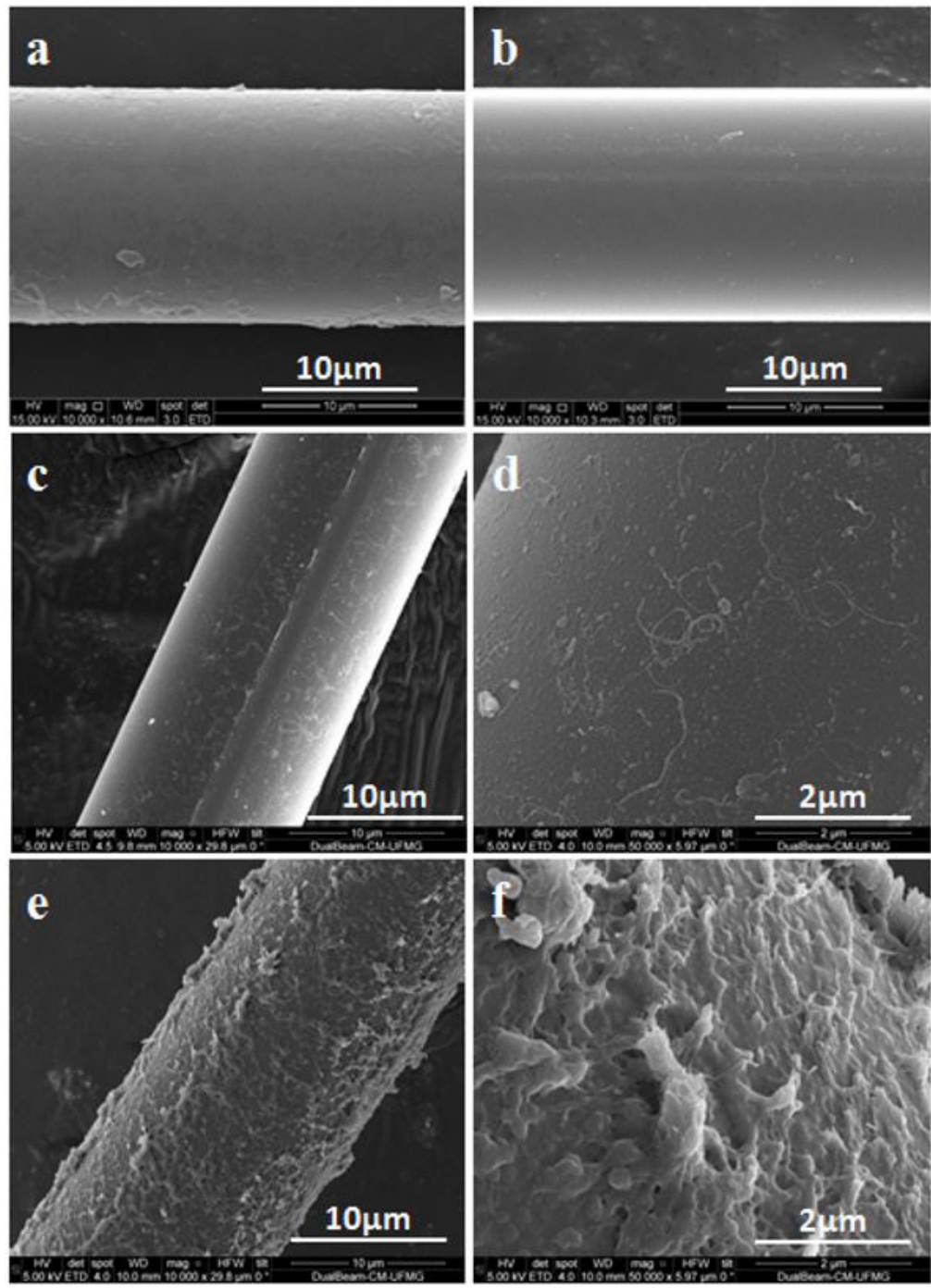

Figure 3. SEM images of glass fibers: (a) commercial; (b) untreated; (c), (d) GF-5BL; (e), (f) GF-20BL. 

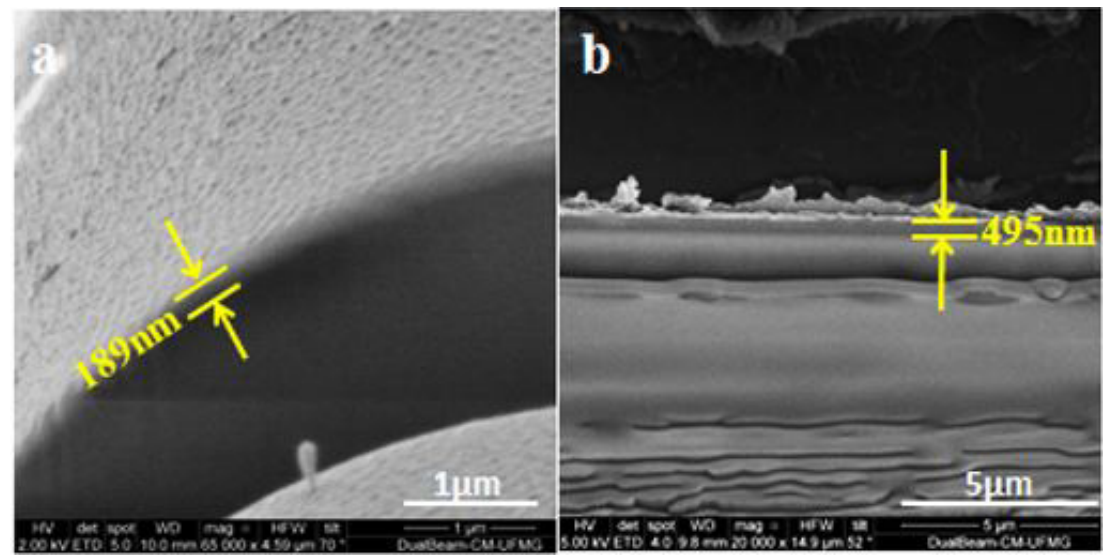

Figure 4. SEM-FIB images of cross sections of FIB milled fibers: (a) GF-5BL; (b) GF-20BL.
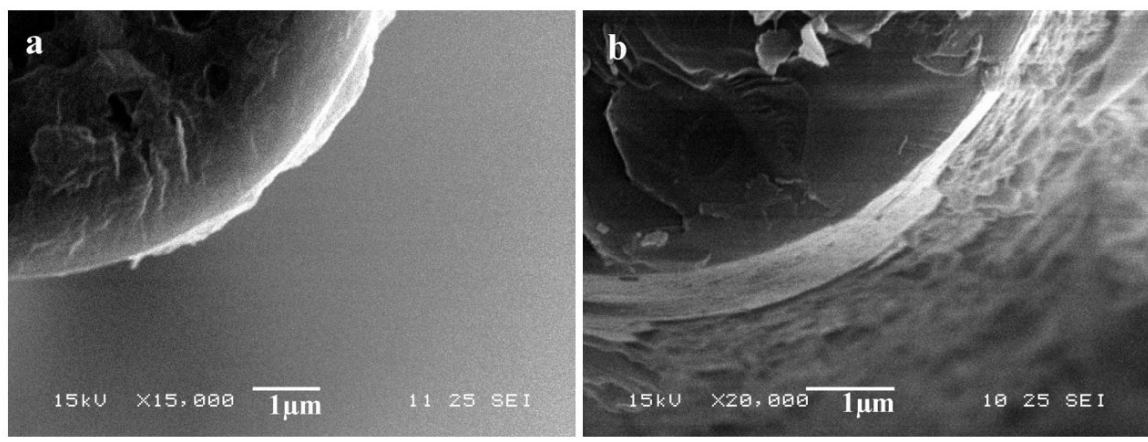

Figure 5. SEM images of cross sections of mechanically cut fibers: (a) GF-5BL; (b) GF-20BL.

observed with the formation of a coating along all the fiber. The cross view of the GF-20BL after FIB milling is shown in Figure $4 \mathrm{~b}$. The thickness of the coating could be assessed as $400-500 \mathrm{~nm}$. It was not possible to observe the individual carbon nanotubes since they were embedded in the thick polymeric coating.

Additional SEM images were acquired for glass fibers which were cross sectioned by transverse cutting (Figure 5). It is possible to observe that the coating thickness initially assessed by localized FIB-milling on the glass fiber surface is actually variable along the fiber.

The nanocoating deposited by LbL method on glass fibers is a novel application. In this work the obtained values for the coating thickness have the same order of magnitude of values reported by other authors ${ }^{[5,8]}$ although a different method is used.

Raman spectroscopy, a powerful tool for carbon nanotubes characterization, was employed to demonstrate the deposition of CNTs on GF surface. In Figure 6, characteristic peaks of CNTs are identified. The D band derived from defects in the nanotube wall is found at $1326 \mathrm{~cm}^{-1}$. The G band which represents the crystalline graphitic and in-plane vibrations of $\mathrm{sp} 2$ carbon is displayed at $1580 \mathrm{~cm}^{-1}$ and $\mathrm{D}^{*}$ band which represents the overtone of disorder is found at $2645 \mathrm{~cm}^{-1[21]}$. The presence of the same Raman peaks on the modified GFs proved that carbon nanotubes were successfully incorporated

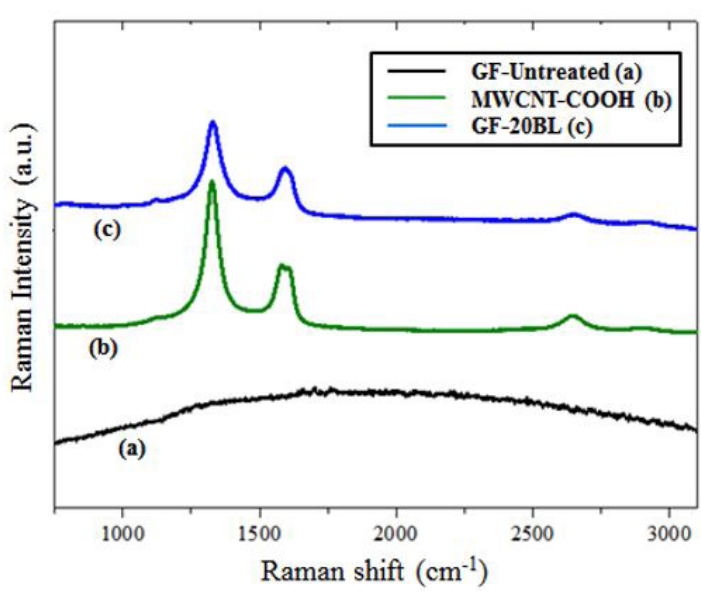

Figure 6. Raman spectra of GF-untreated, MWCNT-COOH and GF-20BL.

within the LbL layers. For the untreated glass fiber, no peak is observed.

Thermogravimetric analysis was employed to get information on the coating weight content. TG curves for the untreated and modified glass fibers are seen in Figure 7. For untreated and 5BL glass fibers, small mass 
fluctuations are observed. For the untreated glass fibers, this TG result confirmed SEM results that showed that the removal of commercial sizing was successful via matrix burnoff and acid digestion. For 5BL glass fibers, a range of $100-200 \mathrm{~nm}$ for the coating thickness was estimated by SEM but variations along and between fibers can occur, leading to a lower weight loss. Moreover, $100 \mathrm{~nm}$ polymer based coatings in $15000 \mathrm{~nm}$ thick glass fibers (with densities much higher than the density of the polymer coatings) result in a very low change of weight (around 1\%) of the system that may be within the measurement error of the analytical technique (i.e. TGA).

TG curve for glass fibers coated with 20 BL showed $6.1 \%$ mass loss which can be assessed as an approximation of the mass content of LbL coating deposited on those fibers. The value found is lower than the actual one since it is known that PSS burning leads to inorganic by-products of high stability due to the presence of $\mathrm{Na}^{+}$in its structure ${ }^{[22]}$.

\subsection{Composites characterization}

\subsubsection{Physical and thermal properties}

The density values at $23^{\circ} \mathrm{C}$, the GF content and the void volume obtained for the prepared composites are reported in Table 1.

Changes in density of a same material can occur due to localized crystallinity and/or to different proportions of resin

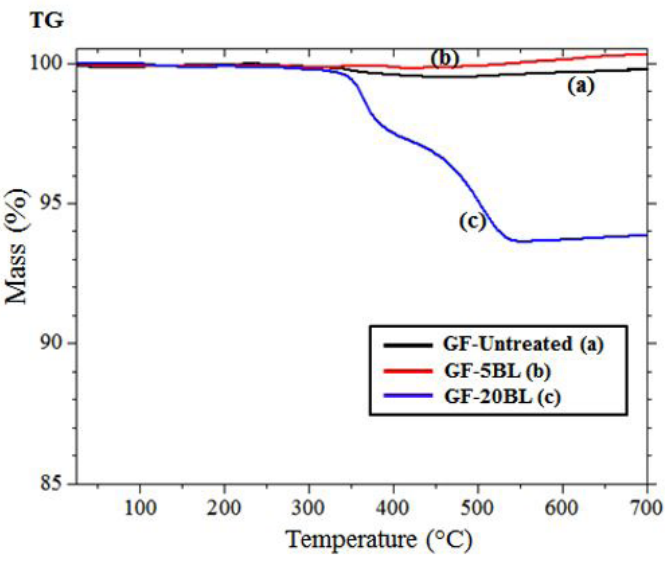

Figure 7. TG curves for GF-untreated, GF-5BL and GF-20BL. and glass fiber (ASTM D792). Comparing the density values among the composites, a mean of $1.072 \mathrm{~g} / \mathrm{cm}^{3}$ and a standard deviation of $0.001 \mathrm{~g} / \mathrm{cm}^{3}$ indicate good process repeatability on composites fabrication. Comparing the glass fiber content among the composites, a mean of $25.62 \mathrm{wt} \%$ and a standard deviation of only $0.39 \mathrm{wt} \%$ was found, corroborating the idea of good process repeatability. The influence of the fiber content on the flexural properties will not be taken into account since a small variation among the composites was obtained.

The obtained coatings on the fibers are constituted by the polymers PDDA and PSS and by the carbon nanotubes. Densities of those constituents are similar to the density of the composite matrix (polypropylene, $0.9 \mathrm{~g} / \mathrm{cm}^{3}$ ). Considering also that the content of the coated fibers in the composites is relatively low (around $25 \mathrm{wt} \%$ ) and that the coating of nanometric dimension is just at the fibers surface, the density of the composites will be not significantly influenced by the coating. The other parameters on Table 1 will not be influenced by the coating as well, since the procedure for obtaining fiber content and void volume is a burnoff in a furnace at $650^{\circ} \mathrm{C}$ which burns also the polymer content (including the polymeric coating).

The mean value around $0.9 \%$ for the void volumes indicates a good quality composite (ASTM D2734). The high standard deviation can be explained by the fact that as the void content gets lower the error in resin density gets increasingly more important. According to ASTM D2734, ideal measurements of density should have an uncertainty of less than $0.0005 \mathrm{~g} / \mathrm{cm}^{3}$, but a $0.005 \mathrm{~g} / \mathrm{cm}^{3}$ was found.

The relevant thermal properties (melting temperature peak $T_{M, P E A K}$, melting enthalpy $\Delta H_{M}$ and relative crystallinity $X_{C}$ ) of the prepared composites are summarized in Table 2. All composites presented a single endothermic peak with very similar positions, suggesting that the modification of the GFs did not affect the melting temperature of the composites. The similar values of the relative crystallinity (with $1 \%$ max. variation) show that the modification of the GFs did not influence the crystallization degree.

\subsubsection{Morphology}

For glass fiber reinforced composites, the morphology of the fracture surface can give information related to the adhesion of fiber-matrix interface. High interfacial adhesion represents an essential key for obtaining high-performance composites $^{[5-6]}$.

Table 1. Density and constituents content for the prepared composites.

\begin{tabular}{cccc}
\hline Composite & Density $\left(\mathbf{g} / \mathbf{c m}^{3}\right)$ & GF content (wt\%) & Void volume (\%) \\
\hline PP-GF-Untreated & $1.071 \pm 0.004$ & $25.49 \pm 0.13$ & $0.83 \pm 0.10$ \\
PP-GF-5BL & $1.071 \pm 0.004$ & $26.05 \pm 0.77$ & $1.27 \pm 0.60$ \\
PP-GF-20BL & $1.073 \pm 0.006$ & $25.31 \pm 0.40$ & $0.51 \pm 0.31$ \\
\hline
\end{tabular}

Table 2. Relevant thermal properties of the prepared composites.

\begin{tabular}{cccc}
\hline Composite & $\mathbf{T}_{\text {m,peak }}\left({ }^{\circ} \mathbf{C}\right)$ & $\Delta \mathbf{H}_{\mathbf{m}}(\mathbf{J} / \mathbf{g})$ & $\mathbf{X}_{\mathbf{c}}(\%)$ \\
\hline PP-GF-Untreated & 165.8 & 64.0 & 30.9 \\
PP-GF-5BL & 165.9 & 66.0 & 31.9 \\
PP-GF-20BL & 166.2 & 65.0 & 31.4 \\
\hline
\end{tabular}



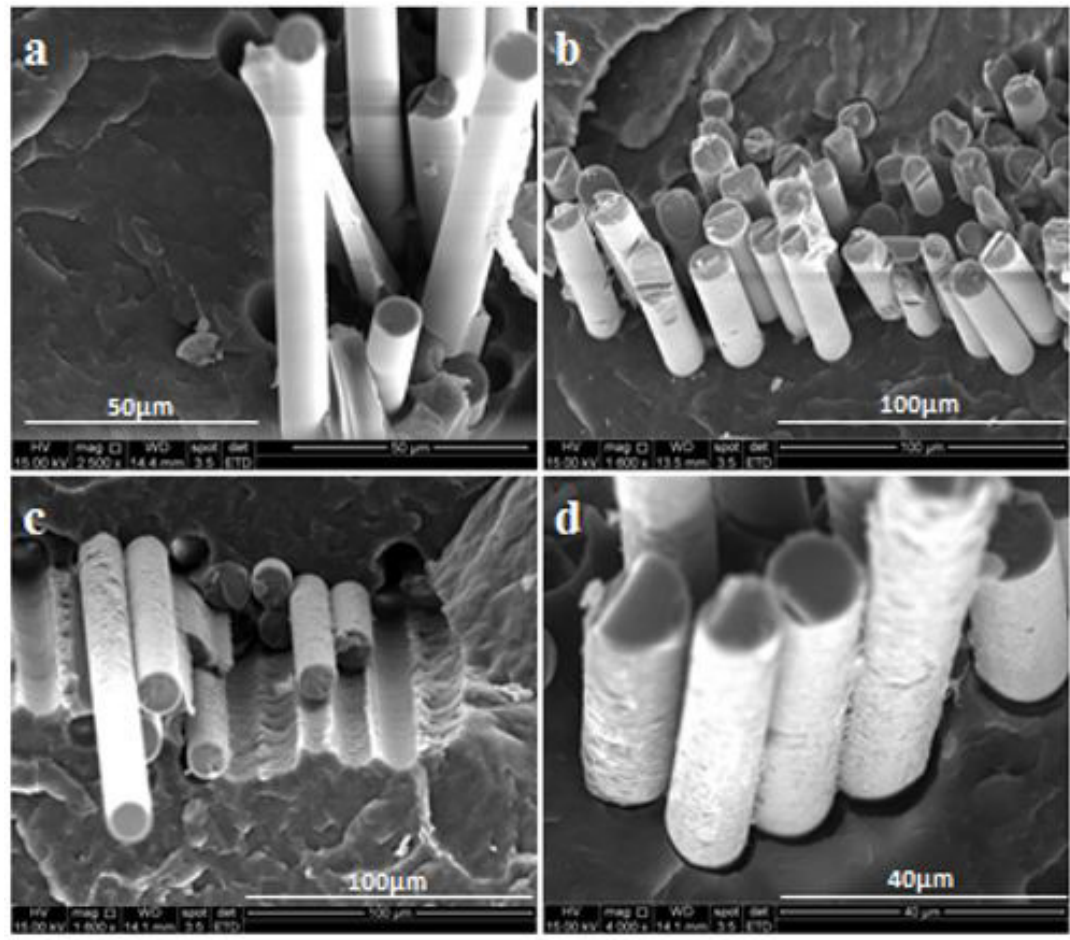

Figure 8. SEM images of the fracture surfaces of the composites: (a) PP-GF-untreated; (b) PP-GF-5BL; (c) PP-GF-20BL; (d) PP-GF-20BL 4,000x magnification.

The images obtained by SEM for all composites (Figure 8) indicate that the fracture occurred predominantly by interfacial debonding with many fibers pull-out. The fibers without coating (PP-GF-untreated) failed by progressive fiber pull-out and debonding. The extensively pulled-out fibers fractured with different lengths could indicate that the damage initiated from several locations along the interface ${ }^{[5]}$. The coated fibers failed transversely across the specimen with more uniform length distribution although debonding and pull-out are also the main fracture micromechanism.

The smooth and clean surface of the fibers without evidence of adhered resin suggests a low adhesion condition with the matrix and therefore a weak interface. The interface between polymer and GFs plays an important task in controlling some of the mechanical properties as tensile and flexural strenght. The fiber-matrix adhesion is confined to the interface where stress-transfer shall occur ${ }^{[4-6]}$. Thus the results presumably indicate that the composites will not present an efficient load transfer from the matrix to the reinforcement phase (GFs) when subjected to mechanical stress.

For the glass fibers coated with 20 bilayers, the nanocomposite coating appears intact indicating a strong bond to the fiber and no changes due to the composite processing steps (Figure 8d).

\subsubsection{Flexural mechanical properties}

Stress vs. strain curves for all the evaluated composites are shown in Figure 9. The curves were chosen from the specimen most representative of the mean results. Flexural Modulus and flexural strength are reported in Table 3. The flexural strength was calculated at $5 \%$ of strain since the samples did not show breaking before that strain.

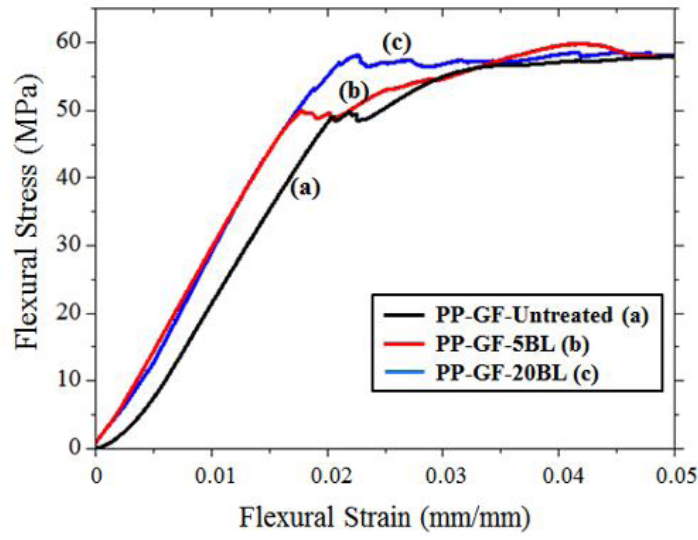

Figure 9. Flexural stress-strain curves for the prepared composites.

It can be noticed in Figure 9 that the presence of LbL layers on GFs modified the stress vs. strain curves. The total area under the curve assigned to the PP-GF-20BL composite is higher than the area under the other curves, meaning that the presence of the 20 bilayers was useful in increasing toughness of the material. This behavior can be attributed to a 'healing' effect in which GF's micro cracks are filled by the coating and severe fiber surface flaws are eliminated due to an increased crack tip radius ${ }^{[5,23]}$. Moreover, the presence of the polymer coating at the interface can provide mechanism for energy dissipation during crack propagation. 
Table 3. Flexural mechanical properties for the prepared composites.

\begin{tabular}{ccc}
\hline Composite & $\begin{array}{c}\text { Flexural Modulus } \\
\text { (MPa) }\end{array}$ & $\begin{array}{c}\text { Flexural Strength } \\
\text { (MPa) }\end{array}$ \\
\hline PP-GF-Untreated & $2730 \pm 417$ & $56.4 \pm 4.0$ \\
PP-GF-5BL & $2921 \pm 264$ & $56.4 \pm 2.5$ \\
PP-GF-20BL & $3174 \pm 183$ & $57.5 \pm 1.0$ \\
\hline
\end{tabular}

The mean values for the Flexural Modulus indicate an increase in this property as the number of bilayers rises (Table 3). The PP-GF-20BL composite exhibited an increase of $16.3 \%$ when compared to the composite with untreated fibers and $8.7 \%$ when compared to PP-GF-5BL. The elastic Modulus is measured at very low deformation and in this condition (close to zero strain) materials react separately to an atomic-molecular level. Thus, the Modulus prediction is not influenced by the low interfacial adhesion observed between fiber and matrix and the properties of each single component become more important ${ }^{[4]}$. We suggest that an improvement in the glass fibers individually due to the presence of carbon nanotubes on their surface substantially increased the stiffness of the system. Coatings containing carbon nanotubes on GFs are useful for enhancing fiber's mechanical properties ${ }^{[5,8]}$. The coating's Modulus and thickness can be also associated as reasons for the results ${ }^{[23]}$.

Nevertheless it is known that mechanical damage on carbon nanotubes, i.e. breakage, induced by high-power tip sonication leads to defective carbon nanotubes with critical reduced length ${ }^{[24]}$. The preparation of the MWCNT-COOH suspension with $30 \mathrm{~min}$ of tip sonication in this work was necessary to achieve a homogeneous and stable suspension in PSS. This process could impair the mechanical properties associated to the defective CNTs thus bringing the coating Modulus to smaller values. The Modulus values obtained for the final composites would also be influenced in a similar way.

There was no significant improvement on the flexural strength among the composites (Table 3). The mechanical strength is highly influenced by the interface adhesion since the maximum stress that material withstands relies on the capability of transferring load between the matrix and the fiber ${ }^{[4]}$. The results of SEM for the crio-fractured surfaces (Figure 8) indicated a low-adhesion condition between GFs and PP. Consequently it was expected that the flexural strength values for the modified GF composites became similar to the untreated GF composite due to ineffective load transfer at the interface.

Potential reason for the low adhesion is the lack of acid chemical groups on polypropylene capable to interact with electron donor sites on the fiber surface which was coated by the polar PDDA/PSS layers ${ }^{[21]}$. The LbL method makes use of polar constituents since it is based on cationic and anionic electrostatic interactions for the construction of the bilayers. On the other hand, the PP is a non-polar polymer. Thus it is possible that this result was related to the lack of chemical affinity between the PP and the LbL components. However, due to its versatility, the LbL technique can provide ways to overcome this observed lack of adhesion. By changing the types of polymers deposited through the
LbL technique, e.g. by using ionic polymers with alkyl groups in the last deposited bilayer ${ }^{[25,26]}$, it could be possible to increase the affinity between the LbL coating and the polymer matrices in future works.

\section{Conclusions}

In summary, carboxylic acid functionalized multiwall carbon nanotubes were dispersed in PSS aqueous solution and a homogeneous stable dispersion was achieved. The dispersion was used as an anionic polyelectrolyte in LbL system to successfully deposit a nanocomposite coating (PDDA//MWCNT-COOH/PSS) on glass fibers surface as proved by SEM and Raman characterization. TGA measurements have shown an estimated coating content on the fiber around $6 \mathrm{wt} \%$ for 20 bilayers. The nanocomposite coating has created a new complex interface between fibers and PP matrix when bidirectional composites were fabricated. The flexural mechanical properties of the composites were analyzed, showing an increase of $16.3 \%$ in the Flexural Modulus and toughness for the PP-GF-20BL composite when compared to PP-GF untreated. Flexural strength was not affected by the GF coating. The results of this work proved that the LbL technique can be used to modify the interface of polymer composites and to incorporate nanocomponents (such as carbon nanotubes) within their interfacial region. The possibility of tailoring the composition and structure of the interface in polymer composites through the use of the LbL technique can allow the construction of interfaces that can perform multiple tasks, such as increasing toughness and encapsulating active components.

\section{Acknowledgements}

The authors would like to acknowledge CAPES, CNPq, FAPEMIG, INCT Acqua and Center of Microscopy of the Federal University of Minas Gerais for providing the equipment, technical and financial support for all experiments. Part of this research was conducted at FCA Fiat Chrysler Automobiles, Betim, Brazil.

\section{References}

1. Godara, A., Gorbatikh, L., Kalinka, G., Warrier, A., Rochez, O., Mezzo, L., Luizi, F., Van Vuure, A. W., Lomov, S. V., \& Verpoest, I. (2010). Interfacial shear strength of a glass fibre/ epoxy bonding in composites modified with carbon nanotubes. Composites Science and Technology, 70(9), 1346-1352. http:// dx.doi.org/10.1016/j.compscitech.2010.04.010.

2. Meiners, A., Ohms, G., Leck, M., Vetter, U., \& Abel, B. (2012). Modifying glass fiber size by plasma treatment. Journal of Adhesion Science and Technology, 26(10-11), 1611-1627. http://dx.doi.org/10.1163/156856111x618443.

3. Zinck, P., Pay, M. F., Rezakhanlou, R., \& Gerard, J. F. (1999). Mechanical characterisation of glass fibres as an indirect analysis of the effect of surface treatment. Journal of Materials Science, 34(9), 2121-2133. http://dx.doi.org/10.1023/A:1004572112470.

4. Etcheverry, M., \& Barbosa, S. E. (2012). Glass fiber reinforced polypropylene mechanical properties enhancement by adhesion improvement. Materials, 5(6), 1084-1113. PMid:28817025. http://dx.doi.org/10.3390/ma5061084.

5. Ma, P. C., Liu, J. W., Gao, S. L., \& Mäder, E. (2013). Development of functional glass fibres with nanocomposite coating: a 
comparative study. Composites. Part A, Applied Science and Manufacturing, 44(1), 16-22. http://dx.doi.org/10.1016/j. compositesa.2012.08.027.

6. Chen, J., Zhao, D., Jin, X., Wang, C., Wang, D., \& Ge, H. (2014). Modifying glass fibres with graphene oxide: Towards high-performance polymer composites. Composites Science and Technology, 97, 41-45. http://dx.doi.org/10.1016/j. compscitech.2014.03.023.

7. Russo, P., Acierno, D., Simeoli, G., Iannace, S., \& Sorrentino, L. (2013). Flexural and impact response of woven glass fiber fabric/polypropylene composites. Composites. Part $B$, Engineering, 54(1), 415-421. http://dx.doi.org/10.1016/j. compositesb.2013.06.016.

8. Siddiqui, N. A., Li, E. L., Sham, M. L., Tang, B. Z., Gao, S. L., Mäder, E., \& Kim, J. K. (2010). Tensile strength of glass fibres with carbon nanotube-epoxy nanocomposite coating: Effects of CNT morphology and dispersion state. Composites. Part A, Applied Science and Manufacturing, 41(4), 539-548. http://dx.doi.org/10.1016/j.compositesa.2009.12.011.

9. Decher, G., Lvov, Y., \& Schmitt, J. (1994). Proof of multilayer structural organization in self-assembled polycation-polyanion molecular films. Thin Solid Films, 244(1-2), 772-777. http:// dx.doi.org/10.1016/0040-6090(94)90569-X.

10. Yang, Y. H., Malek, F. A., \& Grunlan, J. C. (2010). Influence of deposition time on layer-by-layer growth of clay-based thin films. Industrial \& Engineering Chemistry Research, 49(18), 8501-8509. http://dx.doi.org/10.1021/ie100499x.

11. Srivastava, S., \& Kotov, N. A. (2008). Composite Layerby-Layer (LBL) assembly with inorganic nanoparticles and nanowires. Accounts of Chemical Research, 41(12), 1831-1841. PMid:19053241. http://dx.doi.org/10.1021/ar8001377.

12. Ribeiro, B., Botelho, E. C., \& Costa, M. L. (2015). Estudo das propriedades elétricas e térmicas de compósitos nanoestruturados de poli(sulfeto de fenileno) reforçados com nanotubos de carbono. Polímeros: Ciência e Tecnologia, 25(1), 94-100. http://dx.doi.org/10.1590/0104-1428.1728.

13. Lopes, M. C., Trigueiro, J. P. C., Castro, V. G., Lavall, R. L., \& Silva, G. G. (2016). Otimização do processo de dispersão de nanotubos de carbono em poliuretano termorrígido. Polímeros: Ciência e Tecnologia, 26(1), 81-91. http://dx.doi. org/10.1590/0104-1428.2087.

14. Loh, K. J., Kim, J., Lynch, J. P., Kam, N. W. S., \& Kotov, N. A. (2007). Multifunctional Layer-by-Layer carbon nanotubepolyelectrolyte thin films for strain and corrosion sensing. Smart Materials and Structures, 16(2), 429-438. http://dx.doi. org/10.1088/0964-1726/16/2/022.

15. Mansur, A. A. P., Nascimento, O. L., Vasconcelos, W. L., \& Mansur, H. S. (2008). Chemical functionalization of ceramic tile surfaces by silane coupling agents: polymer modified mortar adhesion mechanism implications. Materials Research, 11(3), 293-302. http://dx.doi.org/10.1590/S1516-14392008000300011.
16. Ning, N., Zhang, W., Yan, J., Xu, F., Wang, T., Su, H., Tang, C., \& Fu, Q. (2013). Largely enhanced crystallization of semi-crystalline polymer on the surfasse of glass fiber by using graphene oxide as a modifier. Polymer, 54(1), 303-309. http://dx.doi.org/10.1016/j.polymer.2012.11.045.

17. Bao, H., Chen, Q., Zhang, L., \& Chen, G. (2011). Immobilization of trypsin in the layer-by-layer coating of graphene oxide and chitosan on in-channel glass fiber for microfluidic proteolysis. Analyst, 136(24), 5190-5196. PMid:22013584. http://dx.doi. org/10.1039/c1an15690j.

18. Crisp, M. T., \& Kotov, N. A. (2003). Preparation of nanoparticle coatings on surfaces of complex geometry. Nano Letters, 3(2), 173-177. http://dx.doi.org/10.1021/n1025896f.

19. Xin, X., Xu, G., \& Li, H. (2013). Dispersion and property manipulation of carbon nanotubes by self-assemblies of amphiphilic molecules. In S. Suzuki (Ed.), Physical and chemical properties of carbon nanotubes (pp. 255-273). Rijeka: InTech.

20. Di Crescenzo, A., Ettorre, V., \& Fontana, A. (2014). Non-covalent and reversible functionalization of carbon nanotubes. Beilstein Journal of Nanotechnology, 5, 1675-1690. PMid:25383279. http://dx.doi.org/10.3762/bjnano.5.178.

21. Theodore, M., Hosur, M., Thomas, J., \& Jeelani, S. (2011). Influence of functionalization on properties of MWCNT-epoxy nanocomposites. Materials Science and Engineering A, 528(3), 1192-1200. http://dx.doi.org/10.1016/j.msea.2010.09.095.

22. Villetti, M. A., Crespo, J. S., Soldi, M. S., Pires, A. N., Borsali, R., \& Soldi, V. (2002). Thermal degradation of natural polymers. Journal of Thermal Analysis and Calorimetry, 67(2), 295-303. http://dx.doi.org/10.1023/A:1013902510952.

23. Gao, S. L., Mäder, E., \& Plonka, R. (2008). Nanocomposite coatings for healing surface defects of glass fibres and improving interfacial adhesion. Composites Science and Technology, 68(14), 2892-2901. http://dx.doi.org/10.1016/j. compscitech.2007.10.009.

24. Islam, M. F., Rojas, E., Bergey, D. M., Johnson, A. T., \& Yodh, A. G. (2003). High weight fraction surfactant solubilization of single-wall carbon nanotubes in water. Nano Letters, 3(2), 269-273. http://dx.doi.org/10.1021/n1025924u.

25. Liu, X. Q., \& Picart, C. (2016). Layer-by-Layer assemblies for cancer treatment and diagnosis. Advanced Materials, 28(6), 1295-1301. PMid:26390356. http://dx.doi.org/10.1002/ adma. 201502660 .

26. Huang, X., \& Zacharia, N. S. (2015). Functional polyelectrolyte multilayer assemblies for surfaces with controlled wetting behavior. Journal of Applied Polymer Science, 132(45), 42767. http://dx.doi.org/10.1002/app.42767.

Received: Nov. 15, 2016

Revised: Mar: 09, 2017

Accepted: Mar. 14, 2017 